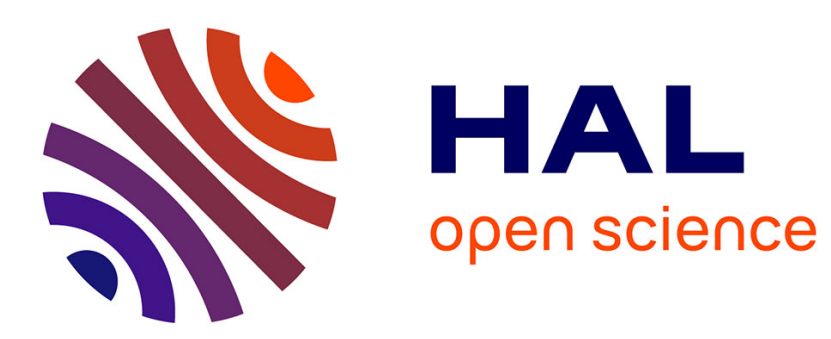

\title{
Being easy to communicate might make verdicts based on confessions more legitimate
} Hugo Mercier, Anne-Sophie Hacquin, Nicolas Claidière

\section{To cite this version:}

Hugo Mercier, Anne-Sophie Hacquin, Nicolas Claidière. Being easy to communicate might make verdicts based on confessions more legitimate. Journal of Cognition and Culture, 2021, 21 (3-4), pp.203-225. 10.1163/15685373-12340104. ijn_03451139

\section{HAL Id: ijn_03451139 \\ https://hal.science/ijn_03451139}

Submitted on 26 Nov 2021

HAL is a multi-disciplinary open access archive for the deposit and dissemination of scientific research documents, whether they are published or not. The documents may come from teaching and research institutions in France or abroad, or from public or private research centers.
L'archive ouverte pluridisciplinaire HAL, est destinée au dépôt et à la diffusion de documents scientifiques de niveau recherche, publiés ou non, émanant des établissements d'enseignement et de recherche français ou étrangers, des laboratoires publics ou privés. 
Being easy to communicate might make verdicts based on confessions more legitimate

Hugo Mercier,1* Anne-Sophie Hacquin1 and Nicolas Claidière2

31 Institut Jean Nicod, Département d'études cognitives, ENS, EHESS, PSL University, CNRS,

Paris, France

$6 \quad *$ To whom correspondence should be addressed: Institut Jean Nicod, pavillon jardin, 29 rue

d’Ulm, 75005 Paris, France; hugo.mercier@gmail.com

Author Note

9 This research was supported by the grant EUR FrontCog ANR-17-EURE-0017 and ANR-10IDEX-0001-02 PSL.

11

12 Data availability statement:

13 Data and scripts used to analyze the data are available online

14 (https://osf.io/ntmqf/?view_only=a1eaf3ffe1cc4ea88d29eef276cf7ec6). 
Abstract

17 In many judicial systems, confessions are a requirement for criminal conviction. Even if

18 confessions are intrinsically convincing, this might not entirely explain why they play such a

19 paramount role. In addition, it has been suggested that confessions owe their importance to their

20 legitimizing role, explaining why they could be required even when other evidence has

21 convinced a judge. But why would confessions be particularly suited to justify verdicts? One

22 possibility is that they can be more easily transmitted from one individual to the next, and thus

23 spread in the population without losing their convincingness. 360 English-speaking participants

24 were asked to evaluate the convincingness of one of three justifications for a verdict, grounded

25 either in a confession, eyewitnesses, or circumstantial evidence, and to pass on that justification

26 to another participant, who performed the same task. Then, 240 English-speaking participants

27 evaluated the convincingness of some of the justifications produced by the first group of

28 participants. Compared to the other justifications, justifications based on confessions lost less of

29 their convincingness in the transmission process (small to medium effect sizes). Modeling

30 pointed to the most common forms the justifications would take as they are transmitted, and

31 results showed that the most common variant of the justification based on a confession was more

32 convincing (small to medium effect sizes).

Keywords: Confessions, legitimacy, communication, cultural transmission. 
38 Someone who confesses should know what they are talking about — their own actions — and, by

39 contrast with denials, confessions do not appear self-interested. This makes confessions

40 extremely convincing (Kassin \& Neumann, 1997; see also, e.g., Henkel, 2008; Neuschatz et al.,

41 2012), and has led many judicial systems to put much weight on them. However, other types of

42 evidence — such as eyewitness testimony — can also be of high evidentiary value, and prove very

43 convincing (e.g., Martire \& Kemp, 2009). It is not immediately clear, then, why confessions

44 should play a paramount role in so many judicial systems, where they are a de facto or even de

45 jure requirement for conviction. This is particularly striking when other types of evidence would

46 be sufficient to convince a judge or a jury, and yet a confession is still required for conviction.

47 These requirements provide incentives for the judge or the prosecution to obtain confessions,

48 requirements which they often meet by means ranging from psychological pressure to torture

49 (Peters, 1996). In turn, these methods increase the rate of false confessions, and thus of wrongful

50 convictions (Peters, 1996). Given that confessions, in spite of their intrinsic convincingness, do

51 not have to play a paramount evidentiary role, and that incentives to obtain them have dire

52 consequences, why are they granted such a special status in many judicial systems?

54 It has been suggested that confessions become a requirement because they render judicial

55 decisions legitimate, as the public finds them convincing (e.g. Langbein, 2012). However, if

56 other types of evidence could convince judges, it is not clear why they could not also convince

57 the public. Here, we attempt to explain why confessions are perceived as a good way of 
58 legitimizing judicial decisions by showing that they make for easy to communicate judgments

59 which can be transmitted with relatively little loss of convincingness.

61 We start by briefly reviewing the role played by confessions in judicial systems across the world,

62 showing that confessions often have a privileged status. We then turn to the problem of the

63 legitimacy of judicial decisions, and the effects this has on judicial institutions. Historical

64 evidence shows that confessions might have been favored because of their perceived capacity to

65 legitimize judicial decisions. We highlight a previously largely ignored issue with legitimizing

66 judicial decisions: the role played by interpersonal communication, and the challenges this raises

67 due to the noisiness of human communication. We formulate our hypothesis-judgments based

68 confessions are a good way of legitimizing judicial decisions because they can be communicated

69 easily while remaining convincing — and test it with two experiments.

71 The role of confessions in judicial systems across the world

73 In many contemporary judicial systems, for which we have reliable statistical data, an

74 overwhelming majority of criminal convictions are based on confessions. In Japan, at least $90 \%$

75 of convictions are based on confessions (Futaba \& McCormack, 1984; Ramseyer \& Rasmusen,

76 2001). In China, defendants confess in three-quarters of cases (Lu \& Miethe, 2003). In the U.S.,

77 where it is preferable to look at plea bargains, a "functional analogue" of confessions (Ramseyer

78 \& Rasmusen, 2001, p. 57), we find that "97 percent of federal convictions and 94 percent of state

79 convictions are the result of guilty pleas" (Missouri v. Frye, 2011, p. 2) (for more on the analogy

80 between confessions and guilty pleas, see, e.g. Redlich, 2010). The importance of confessions is 
81 also attested in many societies throughout history, from Tokugawa Japan (Ishii, 1964), to the

82 ancient middle-east (Boyer, 1964; Brunschvig, 1964), or Rome after Constantine (Thomas, 1986).

84 In all too many cultures, the prominence of confessions is indirectly suggested by the use of

85 judicial torture, whose main function is to extract confessions. In contemporary societies,

86 "torture is used, formally or informally, in one country out of every three" (Peters, 1996, p. 5).

87 The use of torture to extract confessions is also recurrent in the historical record (continental

88 Europe after the thirteenth century, e.g., Langbein, 2012; China since the Han, Conner, 2000;

89 Tokugawa Japan, Ishii, 1964; ancient Athens, Bonner, 1905; Rome after Constantine, Thomas,

90 1986; ancient India, Rocher, 1964; more generally, see Peters, 1996), as well as in the

91 anthropological record (e.g. the Barotse, Gluckman, 1967; or the Haya, where "torture was

92 commonly used to extract a confession of guilt," Cory \& Hartnoll, 1945, p. 271). Beyond

93 outright torture, several judicial processes — such as oaths, ordeals, or lie detectors — have been

94 used - and continue to be used - to threaten the accused and obtain confessions (on ordeals, see,

95 e.g., Hyams, 1981, p. 111; on lie detectors, see, e.g., Segrave, 2004; more generally, see, Mercier,

96 2020; Mercier \& Boyer, 2020).

97

98 In some cultures, the paramount role of confessions is enshrined in the law. The two best studied

99 examples are Imperial China and medieval continental Europe. If confessions had been, in

100 practice, nearly necessary and sufficient for conviction since at least the Tang (618 - 907), they

101 became an absolute necessity under the early Qing (1644 - 1911), with very rare exceptions

102 (Conner, 2000, p. 135). In continental Europe, starting in the thirteenth century, the requirements

103 for a conviction in capital cases came to be strictly regimented: they required either two 
104 eyewitnesses, or a confession (e.g., Langbein, 2012; Lévy, 1964). Since people tend to avoid

105 committing crimes in front of multiple eyewitnesses, "European criminal procedure had no

106 alternative; the law of proof was absolutely dependent upon coerced confessions" (Langbein, 1072012 , p. 8).

108

109 Whether de facto or de jure, confessions are the cornerstone of many judicial systems. If the 110 persuasiveness of confessions is undeniable, their evidentiary value on its own is not necessarily

111 sufficient to explain their overwhelming dominance - in particular the fact that confessions are

112 often mandatory, or quasi-mandatory for conviction, even when other evidence is sufficient to

113 convince judge or jury. A complementary explanation for this dominance is the legitimacy

114 confessions can lend judicial decisions.

115

116 Confessions and the legitimization of judicial decisions

118 It has been argued that the pressure to render legitimate decisions-decisions that are broadly

119 accepted by the population — explains some central features of judicial systems (e.g. Caldeira \&

120 Gibson, 1995; Clark, 2009; Gleeson, 2000; Mercier \& Boyer, 2020; Stephenson, 2004). Of

121 particular relevance, Langbein (2012) has argued that Europe witnessed a shift in the means of

122 legitimizing judicial decisions during the twelfth and thirteenth centuries. In earlier centuries,

123 judicial decisions - in particular on capital crimes - were legitimized by the ordeal and its appeal

124 to divine authority (see, Mercier, 2020). As the practice receded, two alternatives arose to meet

125 the need for legitimizing decisions: the jury in England (although there was still a heavy reliance

126 on confessions, see, Kamali, 2019), and the abovementioned rules of evidence in continental 
127 Europe. Juries fulfilled their legitimizing function because judicial decisions rested with well-

128 known and typically well-respected community members (see also, Fisher, 1997). More

129 relevantly here, the rules of evidence found in continental Europe would have legitimized

130 decisions through the intuitive convincingness of either a combination of two eyewitnesses, or a

131 confession by the accused.

133 A significant piece of evidence showing the legitimizing role played by confessions is the

134 explicit link drawn by medieval jurists between confession and notoriety. Notoriety was the

135 highest level of proof one could attain, designating a "well known fact" (Lévy, 1964, p. 160).

136 Notoriety was originally any fact that the public seemed to agree on (and thus similar to the

137 related concept of fama, see, e.g. Vitiello, 2016), but it was then restricted to things the public

138 could positively know. For a time, this only included things that everyone could directly perceive

139 (Lévy, 1964, p. 161). However, since direct perception by the public is an impossible standard

140 for criminal convictions, in the late twelfth and early thirteenth century, it is confessions that

141 became "the essence of notoriety" (Lévy, 1964, p. 162). There is thus, in medieval Europe, a

142 direct line between concerns about what the public believes (i.e. what is notorious) and the

143 primacy of confessions in judicial decisions. Boyer has suggested that confessions played a

144 similar role in ancient Middle-Eastern law, in which confession "not only made the judge's task

145 easier, but eased the acceptation of the sentence and its execution” (Boyer, 1964, p. 78).

147 The legitimizing role of confessions is also attested by less direct cues, such as the contrasting

148 roles of judicial and extrajudicial confessions. In medieval European law, extrajudicial

149 confessions were only one piece of evidence that judges could consider, by contrast with the 
150 supreme role played by confessions gathered during the official course of the trial—including

151 under torture (Lévy, 1964, p. 152; for a similar observation in ancient Middle-Eastern law, see

152 Boyer, 1964, p. 79). If the main value of confessions was evidential, the difference between

153 judicial and extrajudicial confessions should be largely immaterial.

155 The use of torture to extract confessions is also revealing. In most societies, legal scholars would 156 have been conscious of the unreliability of torture as a mean of gathering evidence (in medieval

157 Europe, “every jurist knew that torture represented a dangerous investigative device,” Fraher, 158 1989, p. 29; on Imperial China, see, Conner, 2000; Imperial Rome, Langbein, 2012, p. 8; ancient 159 Athens, Harrison, 1971, p. 147). Moreover, the official use of torture required that a significant 160 amount of evidence already pointed to a culprit (in Imperial China, "the accused's guilt should 161 already have been established before an official employed torture to obtain a confession” Conner, 162 2000, p. 138; on medieval Europe, see, Langbein, 2012; Lévy, 1964; ancient Athens, Bonner, 163 1905, p. 69; Imperial Rome, Peters, 1996, p. 34). It is thus striking that judicial systems would 164 require the use of torture, unreliable as it was known to be, to complement evidence that was 165 strong enough to have someone tortured in the first place. This suggests that some evidence was 166 deemed insufficient to convict not because of it lacked evidentiary weight (since it was deemed 167 sufficient to have someone tortured), but because it did not make the decision appear legitimate 168 enough.

170 In a variety of judicial systems - most clearly in medieval continental Europe, but also in 171 Imperial China and others - the evidence points to confessions playing a paramount role in 172 legitimizing judicial decisions. However, if it makes sense that confessions should be convincing, 
173 other types of evidence can also be convincing — such as the evidence deemed sufficient to

174 submit someone to judicial torture. If some evidence is good enough to convince the judge, why

175 would it not also be good enough to convince the population?

176

177 Legitimization and the problem of noisy communication

178

179 A legitimate judicial decision is one whose justification is accepted by the population. Judges

180 provide justifications in their judgments, and the people who have been involved in the trial, or

181 who have followed it closely, should be able to evaluate these justifications properly, accepting

182 them as legitimate if they provide good grounds for the verdict. However, in any but the smallest

183 polities, some members of the public will be interested in the adequacy of a trial's outcome

184 without having the opportunity of following the trial closely (even if only because of constraints

185 on the size of the tribunal, restrictions on access, etc.). In modern societies, a proper justification

186 for the verdict is typically available to all in the form of the judgment. However, very few people

187 go to the trouble of perusing the details of judgments. Instead, they hear about the trial's outcome

188 through third parties, such as journalists, or acquaintances who were involved or followed the

189 trial closely.

190

191 The importance of interpersonal communication in the formation of public opinion has already

192 been noted in other domains, for instance in political science (e.g. Druckman et al., 2018; Jensen,

193 2016; Katz \& Lazarsfeld, 1955), or in marketing (e.g. Berger, 2014; De Matos \& Rossi, 2008).

194 There is no reason to doubt that interpersonal communication also plays an important role in

195 shaping public opinion as it relates to trial outcomes. The role of interpersonal communication 
196 would have been even more important in past centuries, when few people could read, and there

197 were no mass media or even local newspapers to publicize the outcome of trials. As a result, the

198 justification offered by the judges for the verdict would often reach members of the public after

199 several episodes of transmission, from the judge, to the audience who attended the trial, to those

200 they shared the news with, to those these people then share the news with, etc. For example,

201 Pettegree (2014, p. 120) notes how, in the sixteenth century, and in spite of the population being

202 largely illiterate, "accounts of notorious crimes circulated widely, and for long after the event,"

203 such accounts often describing the trial subsequent to the crimes.

205 When information is transmitted across multiple steps, it is well known that it will suffer

206 dramatic changes and losses. This phenomenon has been studied with transmission chains

207 studies: experiments in which a participant is provided with a piece of information, must tell it to

208 someone else, who then tells it to someone else, etc. With very few exceptions (e.g., Claidière et

209 al., 2017), such chains lead to rapid losses of content (for reviews, see Mesoudi \& Whiten, 2008;

210 Miton \& Charbonneau, 2018). For example, in Bartlett's pioneering studies, a cogent, five-step,

211 180-words argument related to speciation was reduced, after three transmission episodes to "Mr

212 Garlick says isolation is the cause of modification of species. This seems proved by the test-case

213 of Ireland with regard to snakes, toads and reptiles" (Bartlett, 1932a, pp. 166, 167). A very

214 convincing argument was thus promptly made completely ineffective. The same deterioration

215 would apply to the justification for a verdict. A justification that is very convincing, but that rests

216 on a convergence of arguments, should lose much of its convincingness during the process of

217 transmission, as people modify some elements, and forget others altogether. As a result, only few 
218 members of the public — those with more intimate knowledge of the trial—would find the

219 justification convincing, and it would fail to legitimize the verdict.

221 By contrast with verdicts grounded in relatively long or sophisticated justifications, a verdict

222 based on a confession is easy to transmit while maintaining its convincingness. It's enough to say

223 "he confessed" to provide a solid justification for nearly all criminal verdicts. This justification is

224 readily remembered, and can be easily transmitted. Moreover, a loss of information might make

225 a justification based on a confession more convincing. For example, if someone mentions that

226 the confession might have been coerced, this makes the justification based on the confession less

227 convincing (in some cases at least, see, Kassin \& Wrightsman, 1980, 1981; Kassin \& Sukel,

228 1997). But if the mention of the coercion is forgotten, the justification should become more

229 convincing. By contrast, other justifications, such as "there's evidence" or "someone saw him do

230 it" call for more information to be convincing (What's the evidence? Is the eyewitness reliable?).

232 We thus formulate the following hypothesis: confessions have long played, and still play such a

233 crucial legitimizing role in judicial systems not only because they make for convincing

234 justifications, but also because they make for easy to transmit justifications. If we cannot directly

235 test the historical role played by ease of transmission, we can test whether the basic premise-i.e.

236 that confessions make for easy to transmit justifications - is observed in controlled settings. In

237 two experiments, we test whether justifications based on confessions are easier to transmit, and

238 whether their convincingness is more robust to repeated transmission than that of the two most

239 salient alternatives: eyewitness testimony and circumstantial evidence. 


\section{Experiment 1}

243 In Experiment 1, a first generation of participants was asked to read the descriptions of one of

244 two crimes, provided with one of three arguments to the suspect's guilt (that he confessed, that

245 there were eyewitnesses, or that there was circumstantial evidence), asked to evaluate the

246 suspect's guilt, and then to explain to someone who hadn't been provided with these arguments

247 why the suspect was thought guilty. Participants from a second generation read these

248 explanations, rated how much they believed the suspect guilty, and explained to someone else

249 why he was thought guilty. Finally, the procedure was repeated for participants from a third 250 generation.

252 Participants

253 For each generation, the final sample consisted of 120 English-speaking participants recruited on 254 the online crowdsourcing platform Prolific Academic, and thus 360 participants in total (245

255 women, $\left.M_{\text {Age }}=34.69, S D=12.07\right)$. This sample size was reached after excluding 99 participants

256 who had failed the attention check (see below). All experiments were approved by the

257 [REDACTED], approval number [REDACTED].

259 Materials

260 The description of the two crimes read as follows: "Amanda Jenkins has been found unconscious

261 in her front yard. She had been severely beaten" (Assault), and "Andres Souza's home has been

262 vandalized, with broken furniture, and paint thrown all over" (Vandalism). The arguments read

263 as follows. For the Assault story: 
Confession: "Michael Jenkins, her husband, has been apprehended. After an interrogation by the police, he confessed to having beaten his wife. He said he was jealous and thought he' $d$ found evidence of her unfaithfulness. He said he regretted his actions. However, the police had been detaining him for hours, and they might have exerted undue pressure on Michael before he confessed."

Evidence: "Michael Jenkins, her husband, has been apprehended. The police forensics department found traces of Amanda Jenkins' blood on his hands and clothes, as well as contusions on his hands best explained by violent shocks. Michael has no alibi, and a history of violent behavior." identified him as the culprit, saying they'd seen him arguing with his wife, accusing her of infidelity, then beating her violently and leaving her in the front yard."

For the Vandalism story: interrogation by the police, Ethan Paul confessed to having vandalized the house. He said he and Andres Souza had been fighting over various issues for years, and that Souza had recently violently insulted him. However, the police had been detaining him for hours, and they might have exerted undue pressure on Paul before he confessed." 
Evidence: “Ethan Paul, Andres Souza's neighbor, has been apprehended. The police found in Souza's house a can of spray paint with Paul's fingerprints. At Paul's house, they found a baseball bat, and proved it had been used to vandalize Souza's house. Ethan Paul has no alibi, and a history of violent behavior."

Eyewitness: "Ethan Paul, Andres Souza's neighbor, has been apprehended. A policeman found a maid hidden in a closet, terrified. She said she had seen it was Ethan Paul who'd vandalized the house. She was positive in her identification, being used to see Paul staring at Andres Souza's house as she would go in."

298 We chose a scenario involving a crime against a person, and one a crime against property, since

299 both types of crimes might be processed differently, and this increases the validity of the

300 experiment. A pre-test had suggested that participants found the Evidence and Eyewitness

301 arguments at least as convincing as the Confession argument, so that any bias in the transmission 302 chain in favor of confessions could not be attributed to their initial convincingness (a result that 303 will be confirmed in the guilt ratings of first generation below).

305 It might appear surprising that Confession arguments were not judged more convincing than the 306 other two types of arguments. However, as noted above, even if the confessions ought to be 307 deemed convincing, there is no reason they should be intrinsically more convincing than any 308 other evidence. Moreover, the Confession argument mentioned police pressure, a factor that has 
309 been shown to influence (even if arguably not sufficiently) the convincingness of confessions

310 (Kassin \& Sukel, 1997; Kassin \& Wrightsman, 1980, 1981).

\section{Design and procedure}

313 All participants started by completing a consent form, and finished by completing an attention

314 check and providing demographic information. Participants of the first generation were first

315 presented with a text introduced as having been read in the Monday newspaper, describing the

316 crime (Assault or Vandalism, between-participant). They were then presented with the one of the

317 three seed arguments (Confession, Evidence, Eyewitness, between- participant), introduced as

318 having been read in the Tuesday newspaper. After having read the argument, participants were

319 asked the following question: "How likely do you think it is that [the suspect committed the

320 crime described in the text]?" on a seven-point Likert scale ranging from "Impossible" (1) to

321 "Completely certain" (7), with the central measure "Somewhat likely" (4). Participants were then

322 told that they met a friend who knew about the crime (e.g. about "Amanda Jenkins being beaten

323 and found unconscious in her front yard"), but had no information about the suspect. Participants

324 were asked to answer to questions raised by this friend: "Who do they think did it?" and "Why

325 do they think he's guilty?"

327 Participants in the second generation completed nearly exactly the same survey as those of the 328 first generation. They read about the crime in the Monday newspaper. However, they did not get

329 more information from the Tuesday newspaper (the seeds presented to participants from the first

330 generation). They were told that there was information in the Tuesday newspaper, but that they

331 didn't know what it was. Instead, they met a friend who had more information, and who told 
332 them about who the suspect was, and why they were believed to be guilty. These pieces of

333 information were the answers provided by one of the participants from the first generation. The

334 rest of the survey was identical to the first generation.

336 Finally, participants in the third generation completed exactly the same survey as those of the

337 second generation, the only difference being that the arguments they received came from a

338 participant of the second generation instead of the first.

340 At each generation, the answers to the first question (i.e. "who do they think did it") acted as a

341 supplementary attention check. Participants who were unable to mention the suspect either by

342 name, or through their relationship with the victim (husband or neighbor) were deemed not to

343 have paid sufficient attention and removed. New participants were recruited to fill their place in

344 the transmission chain.

346 All the materials can be found in the Electronic Supplementary Materials (ESM). The survey was 347 displayed on the platform Qualtrics.

\section{Coding}

350 Each post was manually coded by the last author of the article (details can be found in the ESM).

351 The first step consisted in coding whether participants had mentioned the name of the suspect or 352 his relationship to the victim (i.e. husband or neighbor), in their answer to the question "Who do 353 they think did it?" The second step focused on the answer to the question "Why do they think 354 he's guilty?," in order to code which elements of the justification for the verdict participants 
transmitted. The presence or absence of the following elements were coded. In the Confession

356 Condition: confession; explanation of the crime (e.g. his neighbor had recently violently insulted

357 him); police pressures to extract the confession. In the Eyewitness Condition: witness or

358 witnesses; credibility of the witnesses (e.g. the fact that the maid was inside the house when it

359 was vandalized); mention of the number of witnesses; explanation of the crime (e.g. the husband

360 accused his wife of infidelity). In the Evidence Condition: first piece of evidence (the can of

361 spray paint with fingerprints / traces of Amanda Jenkins' blood on Michael Jenkins hands or

362 clothes); second piece of evidence (the baseball bat / contusions on Michael Jenkins hands); third

363 piece of evidence (no alibi); fourth piece of evidence (history of violent behavior). In each

364 condition, one element was deemed to be the central element: the confession, the presence of

365 eyewitnesses, or the first piece of evidence.

367 To ensure the validity of the coding, an independent coder, blind to our hypotheses, coded $20 \%$

368 randomly selected answers. To measure the inter-rater reliability, we calculated Cohen's Kappa

369 coefficient. Agreement scores among the coders was $84.86 \%$ and the strength of agreement was

370 considered to be substantial.

372 Results and discussion

373 All analyses were done with R (v.3.6.1, R Core Team, 2020), using R Studio (v.1.2.5019,

374 RStudio Team, 2015). We refer to being 'statistically significant' as having a $p$-value lower than

375 an alpha of 0.05 . Standardized coefficients are shown.

377 Comparing the overall guilt ratings 
378 Our main measure is the guilt rating, which is the answer to the question "How likely do you

379 think it is that [the suspect committed the crime described in the text]?" Higher ratings mean that

380 participants rated the suspect as more likely to be guilty. In order to test whether justifications

381 based on confessions, compared to justifications based on eyewitnesses or circumstantial

382 evidence, are more likely to remain convincing (and thus to yield high guilt ratings) across

383 multiple transmission episodes, we use a three-pronged strategy: a three-way analysis of variance

384 (ANOVA) to observe the overall pattern, a slope analysis, and a comparison of the guilt ratings at

385 the first and last generations.

387 First, an ANOVA was conducted to compare the main effects of the type of clue (Confession, 388 Eyewitness, Evidence), the generation (First, Second, Third), and the interaction between the 389 type of clue and the generation on the guilt rating. There was a medium effect of the generation $F$ $390(1,359)=51.09, p<.001, \eta^{2}=0.12$, with participants from the first generation $(M=5.17, S D=$ 391 0.90) rating the suspect as more guilty than participants from the second generation $(M=4.57$, $392 S D=0.92)$, Welch's $t(237.86)=5.09, p<.001, d=0.67$, and participants from the second 393 generation rating the suspect as more guilty than participants from the third generation $(M=4.32$, $394 S D=0.94)$, Welch's $t(237.89)=2.07, p=.039, d=0.27$. The type of clue had no influence on 395 guilt ratings, $F(2,359)=0.27, p=.77, \eta^{2}=0.001$. Crucially, there was a small effect of the 396 interaction between the type of clue and the generation on the guilt imputed to a suspect, $F$ (2, $397359)=3.37, p=.03, \eta^{2}=0.02$. The interaction is detailed in the post-hoc analyses below and can 398 be visualized in Figure 1. 


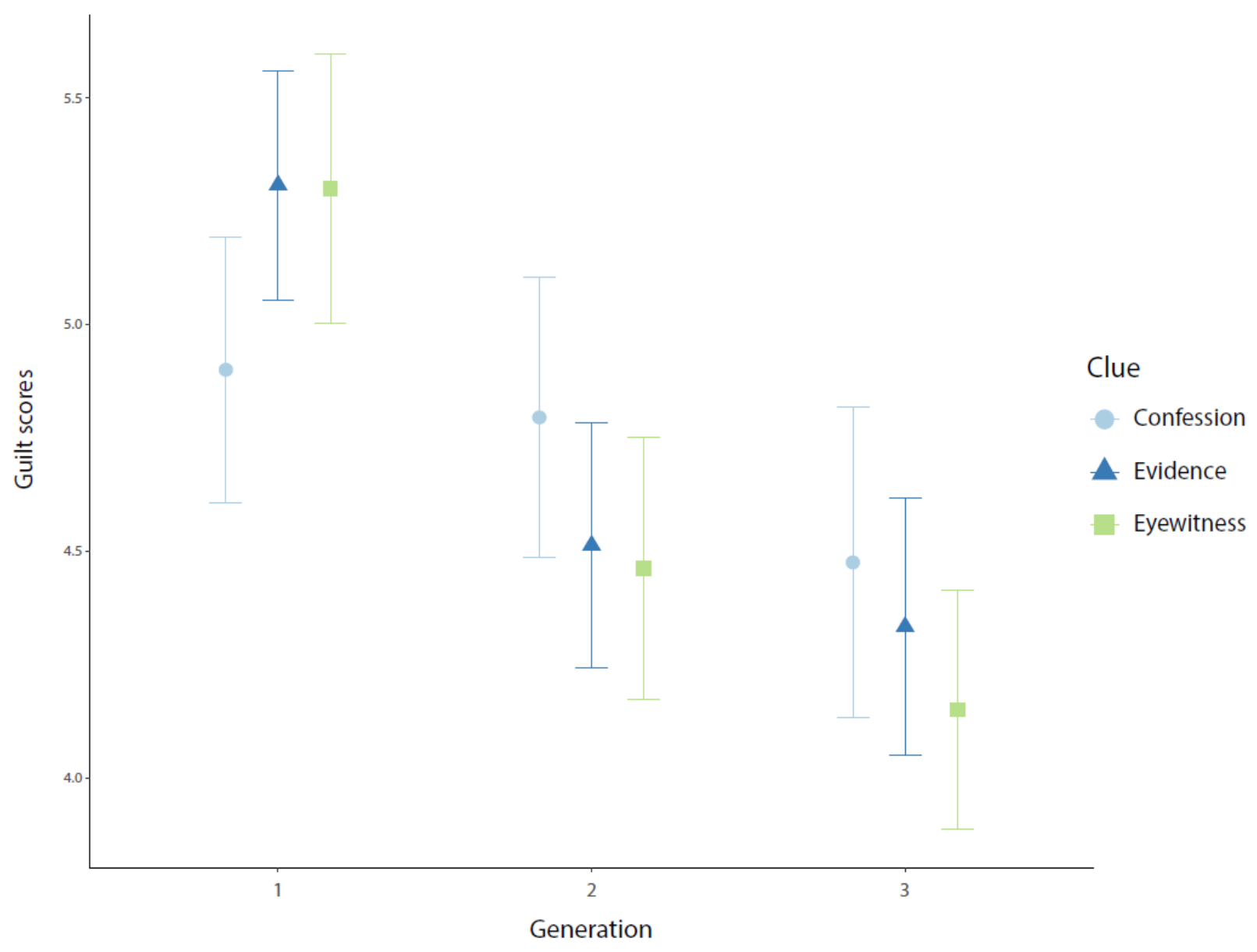

Figure 1. Effects on guilt ratings of the interaction between the generation (first to third) and the

405 nature of the clue presented to the participants (confession, eyewitness, circumstantial evidence).

406 The full range of guilt rating is [1-7].

407

408 Next, we compared the slopes (in absolute value) of the effect on guilt ratings of the generations

409 (i.e. how quickly the guilt ratings drop across the generations). The comparison between the

410 Confession Condition (trend $=0.212, S E=0.103$ ) and the Eyewitness Condition ( trend $=0.575$,

$411 S E=0.103)$ was significant, $t(354)=2.49, p=.035$. However, the difference between the 
412 Confession Condition (trend $=0.212, S E=0.103)$ and the Evidence Condition (trend $=0.487, S E$

$413=0.103)$, was not significant, $t(354)=1.89, p=.144$.

414

415 Finally, we compared the guilt ratings of the first and third generations. In the Confession

416 Condition, there was no significant difference between the guilt ratings of the first generation $(M$

$417=4.9, S D=0.93)$ and of the third generation $(M=4.48, S D=1.09)$, Welch's $t(76.16)=1.88, p$

$418=.06, d=0.42$ (small effect). In the Eyewitness Condition, there was a significant decrease in

419 guilt ratings between the first generation $(M=5.3, S D=0.94)$ and the third generation $(M=4.15$,

$420 S D=0.83$ ), Welch's $t(76.92)=5.79, p<.001, d=1.3$ (large effect). In the Evidence Condition,

421 there was a significant decrease in guilt ratings between the first generation $(M=5.3, S D=0.79)$

422 and the third generation $(M=4.33, S D=0.89)$, Welch's $t(76.97)=5.18, p<.001, d=1.17$

423 (large effect).

424

425 Taken together these three analyses suggest that justifications based on confessions, compared to

426 justifications based on eyewitnesses or circumstantial evidence, lost less of their convincingness

427 in the process of repeated transmission.

429 Guilt ratings associated with the central elements

430 Our hypothesis is that justifications based on confessions remain more convincing because they

431 can be expressed succinctly (i.e. "the suspect confessed") and convincingly, while the

432 convincingness of other justifications rests on the conjunction of several elements (e.g. the

433 presence of eyewitnesses, but also their credibility, their number, etc.). As some of these

434 elements are lost in the transmission process, the justifications become less convincing. To test 
435 this hypothesis, we use the same three-pronged strategy as above, but looking at the guilt ratings

436 of the participants who received at least the central element of each justification. As noted in the

437 coding section, the central element was, respectively, the confession, the presence of

438 eyewitnesses, and the first piece of evidence (which was the piece of evidence most likely to be

439 transmitted, see table with the transmission probabilities of each element in the ESM).

441 First, an ANOVA was conducted to compare the main effects of the type of clue (Confession,

442 Eyewitness, Evidence), the generation (First, Second, Third), and the interaction between the 443 type of clue and the generation on the guilt ratings, for participants who received (at least) the 444 central element in the input justification. There was a medium effect of the generation $F(2,303)$

$445=19.07, p<.001, \eta^{2}=0.11$, with participants from the first generation $(M=5.17, S D=0.90)$ 446 rating the suspect as more guilty than participants from the second generation $(M=4.60, S D=$ 447 0.92), Welch's $t(219.21)=4.63, p<.001, d=0.62$, but no difference between the guilt ratings in 448 the second and third generations $(M=4.42, S D=0.96)$, Welch's $t(178.51)=1.35, p=.18, d=$ 4490.20 . The type of clue had no influence on guilt ratings, $F(2,303)=0.77, p=.46, \eta^{2}=0.004$. 450 Crucially, there was a small interaction between the type of clue and the generation, $F(4,303)=$ $4513.38, p=.01, \eta^{2}=0.04$. The interaction can be visualized in Figure 2. 


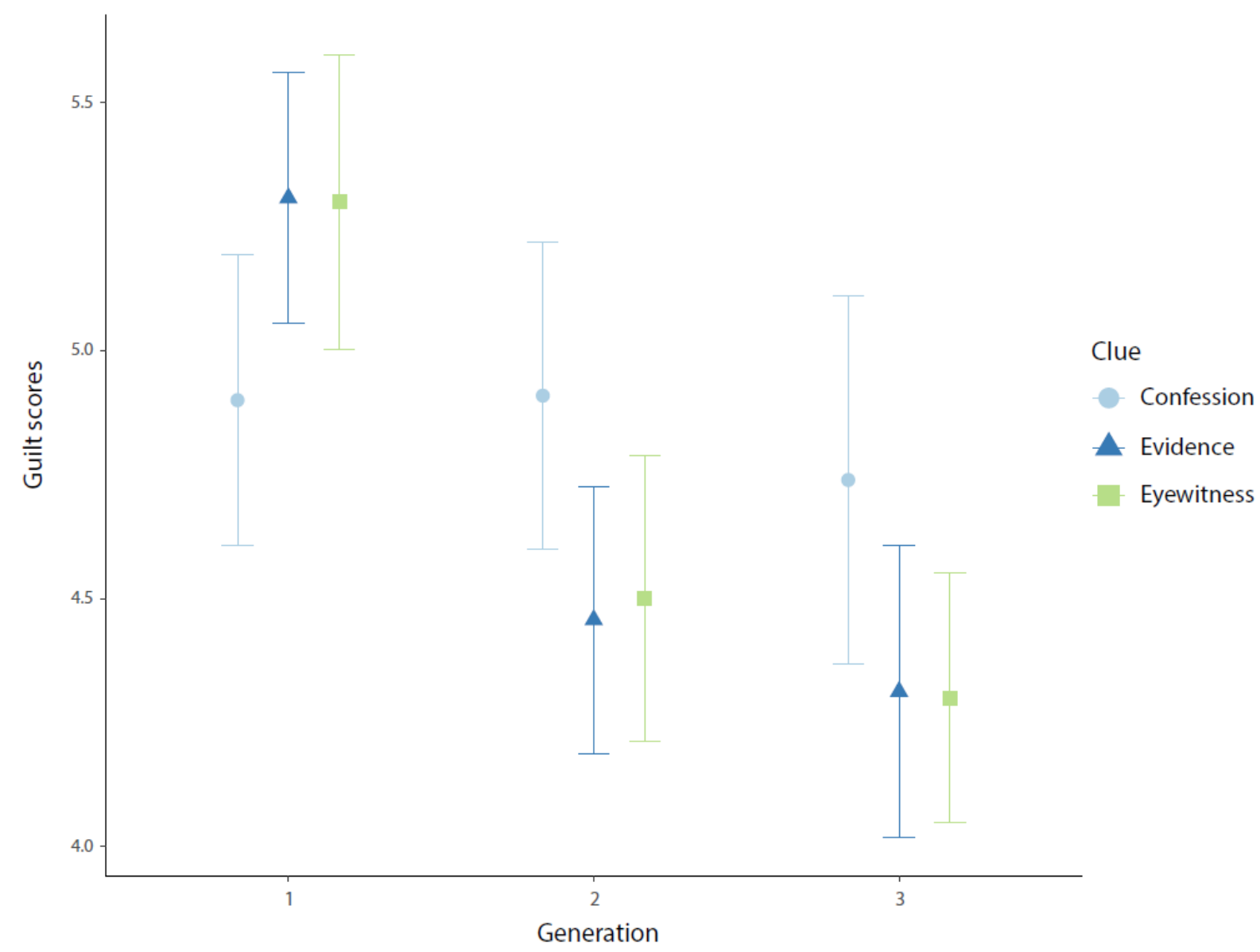

455 Figure 2. Effect on guilt ratings of the interaction between the generation and the nature of the

456 clue presented to the participants, for participants who received at least the central element of

457 the justification. The full range of guilt rating is [1-7].

459 Next, we compared the slopes (in absolute value) of the effect on guilt ratings of the generations 460 (i.e. how quickly the guilt ratings drop across the generations). The comparison between the 461 Confession Condition (trend $=0.07, S E=0.12$ ) and the Eyewitness Condition (trend $=0.52, S E$ $462=0.11)$ was significant, $t(306)=2.74, p=.02$, as was the difference between the Confession 463 Condition (trend $=0.07, S E=0.12$ ) and the Evidence Condition (trend $=0.51, S E=0.11), t$ $464 \quad(306)=2.73, p=.02$. 
466 Finally, we compared the guilt ratings of the first and third generations. In the Confession

467 Condition, there was no significant difference between the guilt ratings of the first generation $(M$ $468=4.9, S D=0.93)$ and of the third generation $(M=4.74, S D=1.18)$, Welch's $t(37.84)=0.56, p$ $469=.58, d=0.16$ (negligible effect). In the Eyewitness Condition, there was a significant decrease 470 in guilt ratings between the first generation $(M=5.3, S D=0.94)$ and the third generation $(M=$ $4714.3, S D=0.79)$, Welch's $t(66.96)=4.82, p<.001, d=1.14$ (large effect). In the Evidence 472 Condition, there was a significant decrease in guilt ratings between the first generation $(M=5.3$, $473 S D=0.79)$ and the third generation $(M=4.3, S D=0.92)$, Welch's $t(63.62)=4.91, p<.001, d=$ 4741.17 (large effect).

476 To some extent, the stability of the justifications based on confessions comes from many 477 participants failing to mention the potential role of police pressure which was present in the 478 initial justification. Justifications that contained this element were much less convincing $(M=4.1$, $479 S D=1.10)$ than those which did not $(M=5.2, S D=0.91)$. Moreover, participants were likely to 480 fail to mention this element: of the participants who received the mention of police pressures, 481 and mentioned the confession in their justifications, only one third (34\%) also mentioned the 482 police pressures. That most participants do not report the potential police pressures thus helps 483 explain the continued convincingness of justifications based on confessions.

485 Taken together these three analyses show that the central element of justifications based on 486 confessions, compared to the central element of justifications based on eyewitnesses or 487 circumstantial evidence, lost less of its convincingness in the process of repeated transmission. 
488 However, we cannot rule out that elements besides the central elements should be well

489 transmitted, and thus that justifications besides convictions remain convincing after multiple

490 transmission. To better understand the effects of repeated transmission on the justifications, we

491 use modeling.

492

\section{Modeling}

494 To better understand the dynamic of information transmission, and its consequences beyond the

495 three generations tested in Experiment 1, we can use models to extrapolate from the current data

496 (on the importance of modeling to link experimental data to cultural trends, see, e.g. Boyd \&

497 Richerson, 2005; Kalish, Griffiths, \& Lewandowsky, 2007; Kirby, Dowman, \& Griffiths, 2007).

498 More specifically, we used evolutionary causal matrices to represent the transformations

499 occurring during transmission (here, the loss in some justificatory elements), and simulate the

500 long term effects of these transformations (Claidière, Scott-Phillips, \& Sperber, 2014; for

501 examples of studies using this method in conjunction with experimental data, see Altay, Claidière,

502 \& Mercier, 2020; Claidière et al., 2018; Miton, Claidière, \& Mercier, 2015). These models

503 describe a situation in which a new group of participants (a new generation of agents) would

504 receive the justifications transmitted by our participants, and would behave in the same way as

505 our participants did, in terms of which elements they mention as a function of which element

506 they had received.

508 The model makes the following assumptions. First, it assumes that the transmission process is

509 similar to a Markov process in being memoryless: agents at each new generation behave exactly

510 like those from other generations, conditional on the input they receive. Second, the model 
511 assumes that the total number of agents per generation remains constant, neglecting in particular

512 the participants who fail to report either the central element (in the Confession and Eyewitness

513 Conditions), or one of the elements (in the Evidence Condition). This assumption is necessary

514 since otherwise all models would lead to the rapid extinction of the phenomenon of interest due

515 to the inevitability of loss in simple transmission chains (a phenomenon well-known at least

516 since Bartlett, 1932). In real life, transmission chains are barely ever linear, with one individual

517 only transmitting to one other individual; instead, chains are full of redundancies, with each

518 individual receiving information from, and transmitting information to, several individuals. This

519 redundancy is typically necessary for cultural elements to persist or to spread (Acerbi \& Tennie,

520 2016; Altay et al., 2020; Claidière et al., 2017; Enquist et al., 2010; Kempe et al., 2014; Morin,

521 2015). The assumption of a fixed total number of agents is a simple way of taking this into

522 account.

524 For each condition, we generated a matrix with the different variants of each justification, as a

525 function of which elements were present (see coding above for more details on the elements). In

526 the Confession Condition, the four variants were: (1) confession only; (2) confession and

527 explanation of the crime; (3) confession and police pressures to extract the confession; (4)

528 confession, explanation of the crime, and police pressures to extract the confession. In the

529 Eyewitness Condition, the four variants were: (1) witness(es) only; (2) witness(es) and

530 credibility of the witness(es); (3) witness(es) and explanation of the crime; (4) witness(es),

531 credibility of the witness(es), and explanation of the crime. In the Evidence Condition, the four

532 variants were: (1) one piece of evidence; (2) two pieces of evidence; (3) three pieces of evidence;

533 (4) four pieces of evidence. 
535 For each of these variants, the data from Experiment 1 tells us, when the variant is received by

536 the participants, what variants are then transmitted. For example, of the 41 participants who

537 received variant (4) of the justification based on confession (the one used as the seed), only one

538 retained all the elements to transmit variant (4), eight transmitted variant (3), seven transmitted

539 variant (2), 17 transmitted variant (1), and eight failed to mention the confession (and were thus

540 not taken into account in the model) (full data available in ESM). Based on the equivalent figures

541 for each variant, Figure 3 provides the output of the model for each of the three conditions.
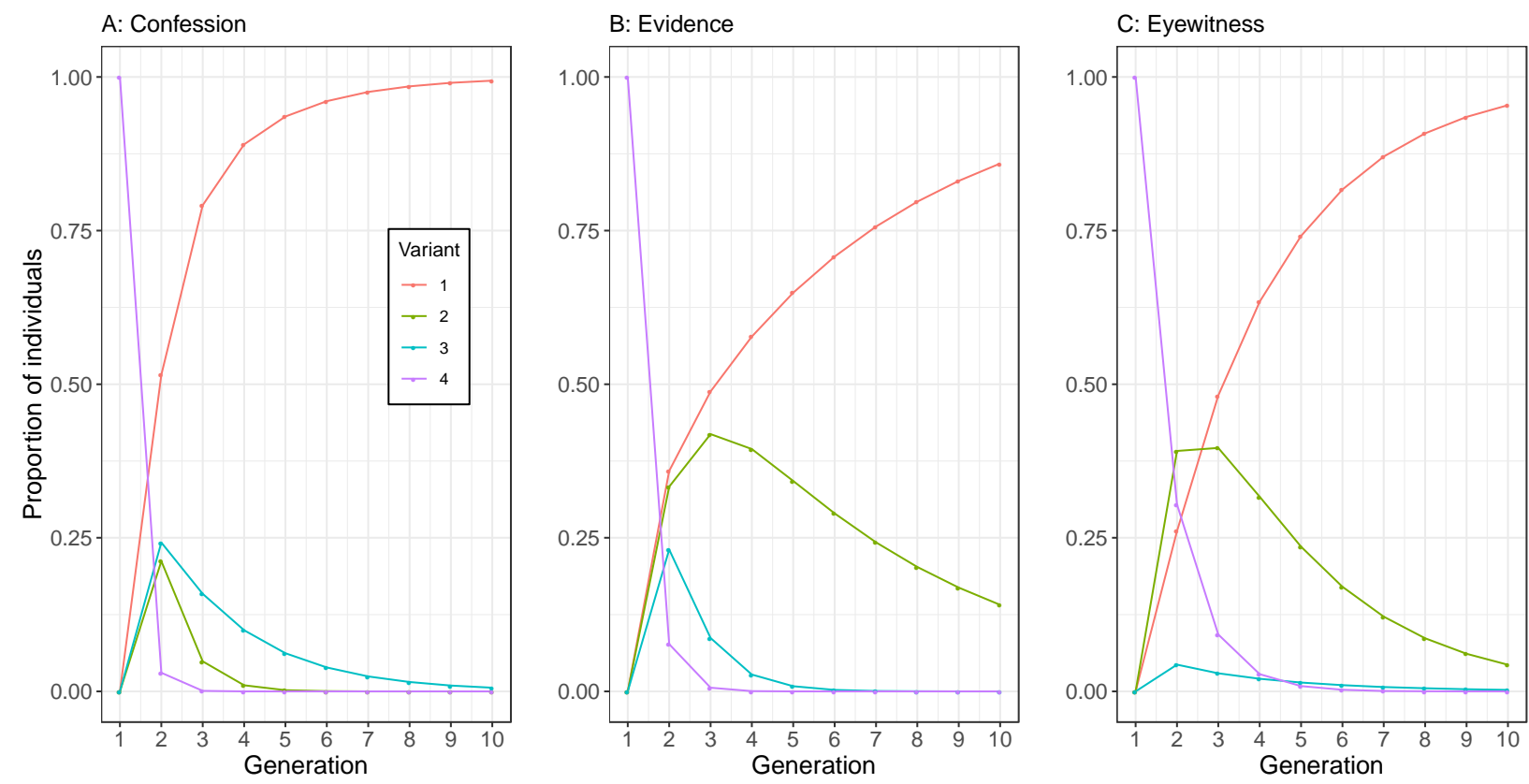

546 Figure 3. Simulation of the evolution of the variants of each of the justifications. The parameters

547 were chosen based on the results of Experiment 1. The initial proportions correspond to the case 
548 in which the full justification (variant (4)) is initially the only variant. See text for details of the

549 variants.

551 These models make it clear which variants dominate in the space between a small number of

552 transmission episodes (two at most), and for at least 10 transmission episodes (a number large

553 enough to reach every member of a medium-scale population if we assume even a minimal

554 amount of redundancy). In the case of justifications based on a confession, the dominant variant

555 is (1) (confession only). In the case of justifications based on eyewitness(es), the dominant

556 variants are (1) (witness(es) only), and (2) (witness(es) and credibility of the witness(es)). In the

557 case of justifications based on circumstantial evidence, the dominant variants are (1) (one piece

558 of evidence), and (2) (two pieces of evidence).

559

560 Participants receiving variant (1) of the justification based on confession $(M=5.2, S D=0.90)$

561 rated the suspect as significantly more likely to be guilty than participants receiving variant (1)

562 of the justification based on eyewitness(es) $(M=4.24, S D=0.94)$, Welch's $t(40.7)=3.76, p<$

$563.001, d=1.05$ (large effect), participants receiving variant (1) of the justification based on

564 circumstantial evidence $(M=4.5, S D=0.86)$, Welch's $t(59.83)=4.76, p<.001, d=1.17$ (large

565 effect), participants receiving variant (2) of the justification based on circumstantial evidence ( $M$ $566=4.24, S D=0.66)$, Welch's $t(55.05)=3.03 p=.004, d=0.78$ (medium effect)), and participants

567 receiving variant (2) of the justification based on eyewitness(es) $(M=4.64, S D=0.99)$, Welch's $t$ $568(62.23)=3.2, p=.002, d=0.79$ (medium effect).

\section{Experiment 2}


571 Experiment 2 seeks to test the robustness of the differences in convincingness of the five variants

572 of justifications shown by the models to be the most common after repeated transmission.

574 Participants

575 We recruited 240 English-speaking participants on the crowdsourcing platform Prolific. We

576 excluded one participant who failed at the attention check (described in the ESM), leaving 239

577 participants $\left(158\right.$ women, $\left.M_{A g e}=35.64, S D=12.44\right)$. This approximatively doubles the sample 578 available for the five relevant variants in Experiment 1.

\section{Materials}

581 For each of the two stories (vandalism and assault), and of the three conditions (Confession,

582 Eyewitness, Evidence), we selected at random three justifications (among those generated in 583 Experiment 1) that fit with each of the five most common variants, for a total of 30 different 584 justifications (all the justifications are available in the ESM).

Design and procedure

587 The design is similar to that of the first generation of Experiment 1, except that participants, after 588 they had provided guilt ratings, were not asked to transmit the justification.

590 Results and discussion

591 Participants receiving variant (1) of the justification based on confession $(M=4.78, S D=0.99)$

592 rated the suspect as significantly more likely to be guilty than participants receiving variant (1)

593 of the justification based on eyewitness(es) $(M=4.21, S D=0.82)$, Welch's $t(92)=3.08, p=$ 
$594.003, d=0.62$ (medium effect), participants receiving variant (1) of the justification based on 595 circumstantial evidence $(M=4.06, S D=0.76)$, Welch's $t(90)=3.97, p<.001, d=0.81$ (large

596 effect), and participants receiving variant (2) of the justification based on circumstantial evidence $597(M=4.24, S D=0.80)$, Welch's $t(92)=2.92, p=.004, d=0.59$ (medium effect) $)$, but not than 598 participants receiving variant (2) of the justification based on eyewitness(es) $(M=4.43, S D=$ 599 0.93), Welch's $t(95)=1.75, p=.084, d=0.37$ (small effect).

601 Taken together with the results of Experiment 1, the results of Experiment 2 show that the most 602 common variant of the justification based on confession is more convincing than the most 603 common variants of the justifications based on eyewitnesses or circumstantial evidence.

\section{Conclusion}

606 In many historical and contemporary judicial systems, confessions play a crucial role, a role that 607 might not be entirely explained by their evidential value; in particular, confessions might also 608 play a legitimizing role. In the present article, we offer further evidence that confessions are apt 609 to play such a role: their convincingness as justifications is robust to repeated transmission. By 610 contrast with justifications based on eyewitnesses or circumstantial evidence, justifications based 611 on confessions retained more of their convincingness as they were transmitted from one 612 participant to the next (Experiment 1). When participants transmit these three types of 613 justifications, some elements of the justifications are lost in the process. In the case of 614 justifications grounded in eyewitnesses and circumstantial evidence, these losses made the 615 justifications much less convincing (e.g. because the number of pieces of circumstantial evidence 616 decreased). By contrast, in the case of confessions, these losses did not affect the convincingness 
617 of the justification, as long as the central element (i.e. the confession itself) was retained. Indeed,

618 in some cases the loss increased the convincingness of the justifications, when it was the mention

619 of potential police pressures that was omitted.

620

621 Modeling showed which types of justifications would be more common after repeated

622 transmission, and the results of Experiments 1 and 2 show that the most common variant of the

623 justification based on confessions was more convincing than the most common variants of the

624 justifications based on eyewitnesses or circumstantial evidence.

625

626 Our experiments have several limitations. First, the convincingness of the confessions was

627 lowered by the mention of potential coercion, an element that could be specifically manipulated

628 in further experiments. Second, we only used a small set of vignettes, which are obviously far

629 from covering the full range of types of justifications for verdicts. Third, the experiments were

630 only conducted in one cultural group, and ought to be replicated in other settings.

632 The stress put on confessions in many judicial systems is theoretically puzzling-i.e. it is not

633 obvious why it should exist — and practically relevant — given that it brings in its wake very

634 problematic features, from torture to false confessions. Our results show that ease of

635 transmission might be one element that compounds the intrinsic convincingness of confessions,

636 making them particularly suited for legitimizing judicial decisions. The present study also show

637 that some light can be shone on such matters by combining a variety of methods: analysis of the

638 historical record (showing, e.g., the explicit importance of legitimacy for medieval jurists),

639 experimental data, and modeling. 
642 Acerbi, A., \& Tennie, C. (2016). The role of redundant information in cultural transmission and cultural stabilization. Journal of Comparative Psychology, 130(1), 62.

644 Altay, S., Claidière, N., \& Mercier, H. (submitted). It happened to a friend of a friend: Inaccurate source reporting in rumor diffusion.

Bartlett, S. F. C. (1932a). Remembering: A study in experimental and social psychology. Cambridge University Press.

648 Bartlett, S. F. C. (1932b). Remembering: A study in experimental and social psychology. Cambridge University Press.

Berger, J. (2014). Word of mouth and interpersonal communication: A review and directions for future research. Journal of Consumer Psychology, 24(4), 586-607.

652 Bonner, R. J. (1905). Evidence in Athenian courts. University of Chicago Press.

653 Boyd, R., \& Richerson, P. J. (2005). The origin and evolution of cultures. Oxford University Press.

Boyer, G. (1964). La preuve dans les anciens droits du proche-Orient. Recueil de La Société Jean Bodin, 18, 62-87.

657 Brunschvig, R. (1964). Le système de la preuve en droit musulman. Recueil de La Société Jean Bodin, 18, 169-186.

659 Caldeira, G. A., \& Gibson, J. L. (1995). The legitimacy of the Court of Justice in the European 660 Union: Models of institutional support. American Political Science Review, 89(2), 356376. 
662 Claidière, N., Amedon, G. K., André, J.-B., Kirby, S., Smith, K., Sperber, D., \& Fagot, J. (2018).

663 Convergent transformation and selection in cultural evolution. Evolution and Human 664 Behavior, 39(2), 191-202.

665 Claidière, N., Scott-Phillips, T. C., \& Sperber, D. (2014). How Darwinian is cultural evolution? Philosophical Transactions of the Royal Society B: Biological Sciences, 369(1642), 20130368.

Claidière, N., Trouche, E., \& Mercier, H. (2017). Argumentation and the diffusion of counterintuitive beliefs. Journal of Experimental Psychology: General, 146(7), 1052-1066.

Clark, T. S. (2009). The separation of powers, court curbing, and judicial legitimacy. American Journal of Political Science, 53(4), 971-989.

Conner, A. W. (2000). True confessions? Chinese confessions then and now. In K. G. Turner, J. V. Feinerman, \& R. K. Guy (Eds.), The Limits of the Rule of Law in China (pp. 132-62). University of Washington Press.

Cory, H., \& Hartnoll, M. M. (1945). Customary Law of the Haya Tribe, Tanganyika Territory (Vol. 7). Frank Cass \& Co.

677 De Matos, C. A., \& Rossi, C. A. V. (2008). Word-of-mouth communications in marketing: A meta-analytic review of the antecedents and moderators. Journal of the Academy of Marketing Science, 36(4), 578-596.

Druckman, J. N., Levendusky, M. S., \& McLain, A. (2018). No Need to Watch: How the Effects of Partisan Media Can Spread via Interpersonal Discussions. American Journal of Political Science, 62(1), 99-112.

683 Enquist, M., Strimling, P., Eriksson, K., Laland, K., \& Sjostrand, J. (2010). One cultural parent makes no culture. Animal Behaviour, 79(6), 1353-1362. 
685 Fisher, G. (1997). The jury's rise as lie detector. The Yale Law Journal, 107(3), 575-713.

686 Fraher, R. M. (1989). Conviction according to conscience: The medieval jurists' debate concerning judicial discretion and the law of proof. Law and History Review, 7(1), 23-88.

Futaba, I., \& McCormack, G. (1984). Crime, confession and control in contemporary Japan. Law Context: A Socio-Legal J., 2, 1.

Gleeson, A. M. (2000). Judicial Legitimacy. Judicial Officers’Bulletin, 12(6), 41-48.

Gluckman, M. (1967). The judicial process among the Barotse of Northern Rhodesia (Zambia). Manchester University Press.

693 Harrison, A. R. W. (1971). The law of Athens (Vol. 2). Clarendon Press.

694 Henkel, L. A. (2008). Jurors' reactions to recanted confessions: Do the defendant's personal and dispositional characteristics play a role? Psychology, Crime \& Law, 14(6), 565-578.

Hyams, P. R. (1981). Trial by ordeal: The key to proof in the early common law. In M. S. Arnold, T. A. Green, S. A. Scully, \& S. D. White (Eds.), On the laws and customs of England: Essays in honor of Samuel E. Thorne (pp. 90-126). University of North Carolina Press.

Ishii, R. (1964). The history of evidence in japan. Recueil de La Société Jean Bodin, 18, 521-534.

Jensen, K. B. (2016). Two-Step and Multistep Flows of Communication. The International Encyclopedia of Communication Theory and Philosophy, 1-11.

702 Kalish, M. L., Griffiths, T. L., \& Lewandowsky, S. (2007). Iterated learning: Intergenerational 703 knowledge transmission reveals inductive biases. Psychonomic Bulletin \& Review, 14(2), $288-294$. 
707 Kassin, S. M., \& Neumann, K. (1997). On the power of confession evidence: An experimental test of the fundamental difference hypothesis. Law and Human Behavior, 21(5), 469-484.

709 Kassin, S. M., \& Sukel, H. (1997). Coerced confessions and the jury: An experimental test of the" harmless error" rule. Law and Human Behavior, 21(1), 27.

711 Kassin, S. M., \& Wrightsman, L. S. (1980). Prior Confessions and Mock Juror Verdicts. Journal of Applied Social Psychology, 10(2), 133-146.

713 Kassin, S. M., \& Wrightsman, L. S. (1981). Coerced Confessions, Judicial Instruction, and Mock Juror Verdicts. Journal of Applied Social Psychology, 11(6), 489-506.

715 Katz, E., \& Lazarsfeld, P. F. (1955). Personal influence: The part played by people in the flow of 716 mass communications. Free Press.

717 Kempe, M., Lycett, S. J., \& Mesoudi, A. (2014). From cultural traditions to cumulative culture: Parameterizing the differences between human and nonhuman culture. Journal of Theoretical Biology, 359, 29-36.

720 Kirby, S., Dowman, M., \& Griffiths, T. L. (2007). Innateness and culture in the evolution of 721 language. Proceedings of the National Academy of Sciences, 104(12), 5241-5245.

722 Langbein, J. H. (2012). Torture and the law of proof: Europe and England in the Ancien Régime. $723 \quad$ University of Chicago Press.

724 Lévy, J. P. (1964). Le problème de la preuve dans les droits savants du Moyen-Age. Recueil de 725 La Société Jean Bodin, 18, 137-167.

726 Lu, H., \& Miethe, T. D. (2003). Confessions and criminal case disposition in China. Law \& $727 \quad$ Society Review, 37(3), 549-578. 
728 Martire, K. A., \& Kemp, R. I. (2009). The impact of eyewitness expert evidence and judicial 729 instruction on juror ability to evaluate eyewitness testimony. Law and Human Behavior, $730 \quad 33(3), 225-236$.

731 Mercier, H. (2020). The Cultural Evolution of Oaths, Ordeals, and Lie Detectors. Journal of 732 Cognition and Culture, 20(3-4), 159-187.

733 Mercier, H., \& Boyer, P. (2020). Truth-making institutions: From divination, ordeals and oaths to 734 judicial torture and rules of evidence. Evolution and Human Behavior.

735 Mesoudi, A., \& Whiten, A. (2008). The multiple roles of cultural transmission experiments in understanding human cultural evolution. Philosophical Transactions of the Royal Society

738 Missouri v. Frye, No. 10-444 (2011).

739 Miton, H., \& Charbonneau, M. (2018). Cumulative culture in the laboratory: Methodological and theoretical challenges. Proc. R. Soc. B, 285(1879), 20180677.

741 Miton, H., Claidière, N., \& Mercier, H. (2015). Universal cognitive mechanisms explain the cultural success of bloodletting. Evolution and Human Behavior, 36(4), 303-312.

743 Morin, O. (2015). How Traditions Live and Die. Oxford University Press.

744 Neuschatz, J. S., Wilkinson, M. L., Goodsell, C. A., Wetmore, S. A., Quinlivan, D. S., \& Jones, N. J. (2012). Secondary confessions, expert testimony, and unreliable testimony. Journal

747 Peters, E. (1996). Torture: Expanded Edition. University of Pennsylvania Press.

748 Pettegree, A. (2014). The invention of news: How the world came to know about itself. Yale $749 \quad$ University Press. 
750 R Core Team. (2020). R: A language and environment for statistical computing. R Foundation $751 \quad$ for Statistical Computing. https://www.R-project.org/

752 Ramseyer, J. M., \& Rasmusen, E. B. (2001). Why is the Japanese conviction rate so high? The $753 \quad$ Journal of Legal Studies, 30(1), 53-88.

754 Redlich, A. D. (2010). False confessions, false guilty pleas: Similarities and differences.

755 Rocher, L. (1964). The theory of proof in ancient Hindu law. Recueil de La Société Jean Bodin, $756 \quad 18,325-371$

757 RStudio Team. (2015). RStudio: Integrated development for R. RStudio. http://www.rstudio.com/ 758 Segrave, K. (2004). Lie detectors: A social history. McFarland.

759 Stephenson, M. C. (2004). Court of public opinion: Government accountability and judicial 760 independence. Journal of Law, Economics, and Organization, 20(2), 379-399.

761 Thomas, Y. (1986). Confessus pro iudicato. Publications de l'École Française de Rome, 88(1), $762 \quad 89-117$.

763 Vitiello, J. C. (2016). Public Justice and the Criminal Trial in Late Medieval Italy. Brill. 764 